\section{An Unusual Case of Fatal Gastrointestinal Bleeding}

In portal hypertension, varices occuring at sites other than the commonly recognized portal systemic anastomoses are rare. The prevalence of these 'ectopic' varices in patients with cirrhosis is $1-3 \%$, and the varices are located in the duodenum, large and small intestines, enterostomy stoma, and rarely in the peritoneum, biliary tree, vagina and bladder $(1,2)$. Small intestinal varices represent one-third of reported cases. Patients with ectopic varices characteristically present with the small or large intestinal variceal bleeding syndrome (2), which comprises fresh blood loss per rectum (without haematemesis), liver disease (usually cirrhosis), and nonbleeding oesophageal varices. In small intestinal ectopic varices, bleeding is usually intermittent, or occurs over a number of days (1, 2 ), which allows localization of the bleeding source by investigative techniques, and appropriate surgery (portocaval shunt) to be performed (2). Previous abdominal or pelvic surgery is known to predispose to ectopic varices. Treatment of oesophageal varices is known to lead to an increased risk of ectopic varices, and bleeding at alternative portal-systemic anastomoses (1).

The case presented here is that of a 29-year-old woman with cirrhosis of unknown aetiology, with a history of sclerosed oesophageal varices, and a Caesarian section. Angiography and venography performed for transplant assessment showed large portal vein collaterals, but no bleeding. Liver function deteriorated rapidly, and she had several episodes of severe mealena. Despite resuscitation attempts, she died before the liver transplant could take place. A post-mortem examination showed evidence of liver failure with portal hypertension. The oesophageal varices were intact, but ectopic varices in the duodenum and jejunum showed rupture, leading to massive blood loss and death. Although there was no evidence of systemic opportunistic infection, microscopic examination of some ruptured varices showed invasive candidal hyphae (indicative of local overgrowth). The case is unusual in that the patient did not present with the small or large intestinal variceal bleeding syndrome, had so rapid and massive a bleed as to be fatal, and the diagnosis of ruptured ectopic varices was made at post-mortem.

\section{References}

1 Labrec D, Benamom JP: Ectopic varices in portal hypertension. Clin. Gastroenterol. 1985; 14 (1): 105-121.

2 Capell MS, Price JB: Characterisation of the syndrome of the small and large intestinal variceal bleeding. Dig. Dis. Sci. 1987; 32 (4): $422-427$.

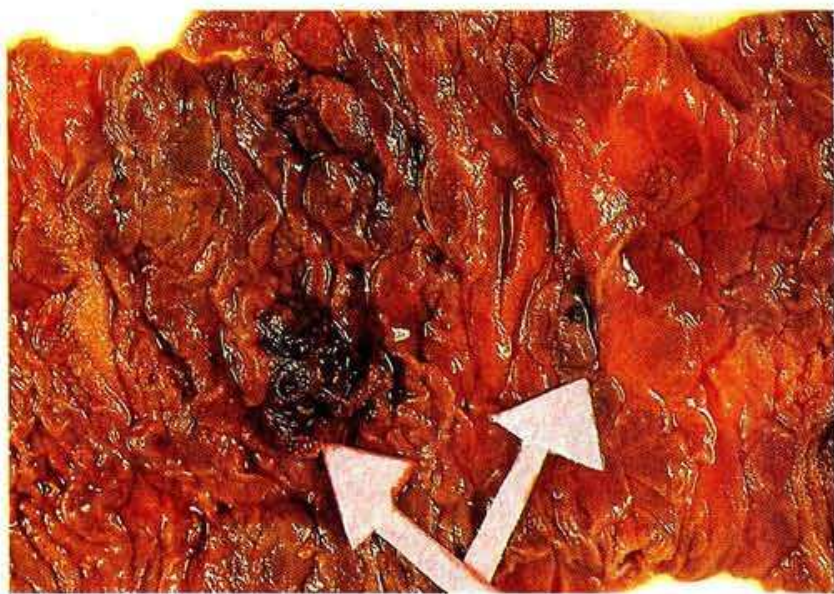

Figure 1: Opened jejunum showing several varices running beneath the mucosa with points of rupture, as indicated by the arrows.

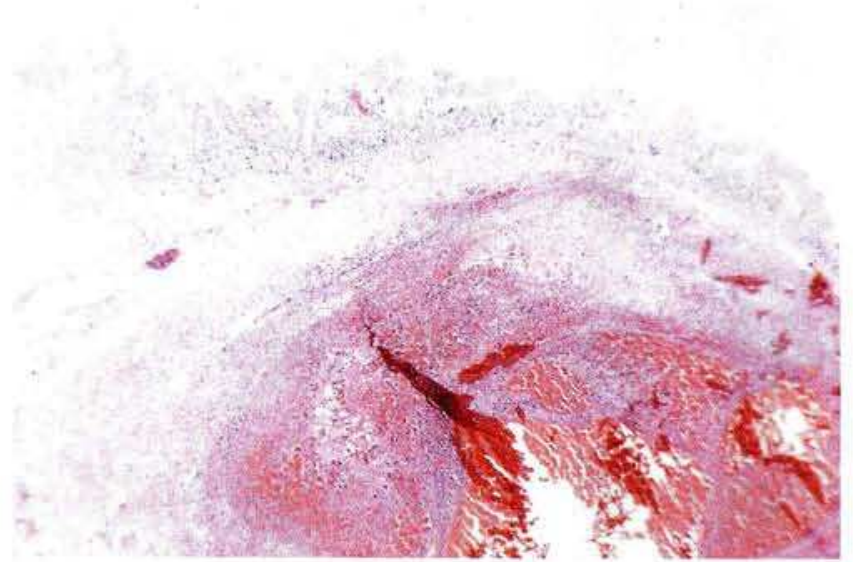

Figure 2: Microscopy showing the small-intestinal mucosa, beneath which is a large varix.

Corresponding Author

Dr. K. L. Ramsden, M.D.,MB ChB MRCpath

Department of Histopathology

Birmingham Maternity Hospital

Edgbaston, Birmingham B15 2BT

United Kingdom 